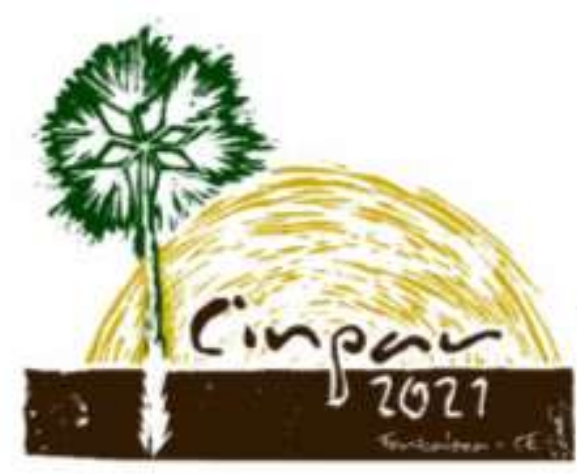

XVII Congresso Internacional sobre Patologia e Reabilitação das Construçōes

XVII Congreso Internacional sobre Patologia y Rehabilitación de las Construcciones

XVII International Conference on Pathology and Constructions Rehabilitation

FORTALEZA (Brasil), 3 a 5 de junho de 2021 https://doi.org/10.4322/CINPAR.2021.071

\title{
Análise da capacidade de captura de dióxido de carbono em peças de pavimento intertravado de concreto.
}

\section{Analysis of the carbon dioxide capture capacity in interlocking concrete pavement pieces.}

\author{
Wemerson ABREU ${ }^{1}$, Marisa LEITÃO², Rafaela FUJITA ${ }^{3}$ \\ ${ }^{1}$ Centro Universitário Christus, Fortaleza, Brasil, wemersonabreulima@hotmail.com \\ ${ }^{2}$ Centro Universitário Christus, Fortaleza, Brasil, marisaleitao43@gmail.com \\ ${ }^{3}$ Centro Universitário Christus, Fortaleza, Brasil, rafaelafujita@hotmail.com
}

\begin{abstract}
Resumo: Para que houvesse o surgimento da vida, como a conhecemos, um processo foi e é fundamental na Terra, o Efeito Estufa. No entanto, com a crescente emissão de gases provocadas pelos humanos ao longo dos anos, sendo o principal, o dióxido de carbono $\left(\mathrm{CO}_{2}\right)$, o desequilíbrio gerado pela ação humana vem acarretando uma série de problemas decorrentes dessa maior concentração de Gases do Efeito Estufa (GEE) na atmosfera. Dessa forma, o presente artigo pretende contribuir para a redução do gás mais relevante para o Efeito Estufa, o dióxido de carbono, por meio de peças de pavimento intertravado de concreto, que através da sua carbonatação, pode vir a ser uma alternativa viável para minimização dos impactos causados pelos seres humanos no meio ambiente. Para tanto, será realizado uma abordagem sobre os principais conceitos acerca da emissão de $\mathrm{CO} 2$ na atmosfera e seus impactos no meio ambiente, discutindo sobre Efeito Estufa, indústria cimentícia, fatores que influenciam a carbonatação, análise da carbonatação e pavimentação com peças de pavimento intertravado de concreto. Desse modo, com o objetivo de analisar a capacidade de captura do $\mathrm{CO} 2$ por peças de pavimento intertravado, serão analisadas amostras sem tratamento de carbonatação e com tratamento, essa última se dividindo em duas frentes, a carbonatação natural e a carbonatação induzida, com o auxílio de equipamentos para medição de profundidade da carbonatação e rompimento das peças de pavimento intertravado de concreto. Com isso, é esperado que as peças carbonatadas tenham uma melhora na resistência a compressão, aumentando sua eficiência e minimizando a quantidade de $\mathrm{CO} 2$ na atmosfera.
\end{abstract}

Palavras-chave: Captura de CO2. Efeito Estufa. Pavimento intertravado. Indústria cimentícia. Carbonatação.

\section{Introdução}

O fenômeno natural do Efeito Estufa tem sido prejudicado devido a ações que elevam as emissões de gases. Dentre os principais Gases de Efeito Estufa (GEE), há o dióxido de carbono (CO2), que segundo Beiroz (2011) é responsável por cerca de $64 \%$ do $\mathrm{GEE}$, decorrente do uso de combustíveis fósseis, queimadas e desmatamentos pelos seres humanos. Para Lira (2020), a preocupação com aquecimento global levou a indústria do cimento a se tornar um alvo com grande potencial para promover significativas reduções, entre elas: adições de subprodutos ao cimento, utilização de combustíveis alternativos para queima, filtros e créditos de carbono. Para Assi et al. (2016), encontrar alternativas ao cimento Portland é de extrema 
importância devido aos altos níveis de emissão de dióxido de carbono associados ao seu processo de fabricação.

O crédito de carbono é uma possibilidade da indústria cimentícia minimizar seus efeitos ao meio ambiente por meio da captura de carbono. Esse processo de captura de $\mathrm{CO} 2$ acontece na carbonatação de produtos à base de cimentos. Possan (2019) define a carbonatação como sendo um processo no qual o dióxido de carbono (CO2), capturado da atmosfera, reage com os produtos carbonatáveis presentes na matriz a base de cimento, formando o carbonato de cálcio ( $\mathrm{CaCO} 3)$ e água ( $\mathrm{H} 2 \mathrm{O}$ ).

No entanto a carbonatação é prejudicial em peças de concreto armado, por causar a despassivação da armadura contida no interior do concreto, que resulta no processo de corrosão, reduzindo a vida útil da estrutura (Rigo, Oliveira e Possan, 2018, p. 3). Porém em contrapartida, em peças sem a presença de armadura, como é o caso do pavimento intertravado, tal fenômeno pode trazer benefícios ao meio ambiente oa diminuir a concentração de $\mathrm{CO} 2$ na atmosfera.

Dessa forma, o pavimento intertravado surge como solução para a minimização dos impactos causados pela indústria cimentícia por ter a capacidade de capturar o carbono do meio ambiente. Além disso, o uso de pavimento intertravado é bastante usual e apresenta vantagens, onde de acordo com Muller (2005), são de fácil execução e exigem pouca manutenção, sem necessidade de equipamentos sofisticados, além de ser possível projetar rodovias desde o tráfego muito leve até o muito pesado usando o mesmo tipo de revestimento, desde que respeitada a classe de resistência.

Considerando a capacidade de captura de carbono por meio da carbonatação de peças de concreto para pavimentação, a presente pesquisa tem como objetivo analisar o comportamento dessas peças ao serem expostas a carbonatação. Para tanto pretende-se analisar profunidade de carbonatação e resistência das peças após carbonatadas.

\section{Metodologia}

\subsection{Materiais}

Para a pesquisa foram selecionadas 30 peças de pavimento, classificadas como do Tipo I conforme a norma NBR 9781:2013. As peças selecionadas são do modelo de 16 faces com dimensões de $24 \times 12 \times 8 \mathrm{~cm}$, e foram obtidas por meio de uma empresa local fabricante de pré-moldados.

Conforme informação repassada pelo fabricante, as peças possuem resistência a compressão de $35 \mathrm{MPa}$ e são utilizados para tráfego de veículos leves, segundo especificado na NBR 9781:2013. Para simular o processo de carbonatação das peças, estas foram inseridas em um tanque de poliestireno expandido com capacidade de $170 \mathrm{~L}$ no qual era inserido o gás carbônico por meio de um extintor de incêndio de CO2.

\subsection{Métodos}

Com o intuito de auxiliar a compreensão dos resultados, as peças selecionadas foram divididas em três grupos, os quais expostos a situações distintas. As peças do grupo 1, denominado de grupo de referência, não foram expostas a nenhuma solicitação, ficando esse grupo protegido em local coberto e fechado. As peças do grupo 2 foram expostas a um processo de carbonatação induzido. As peças desse grupo foram inseridas no tanque de poliestireno expandido e diariamente foi inserido $\mathrm{CO} 2$ por meio de um extintor. As peças do grupo 3 foram expostas a locais próximos de vias de tráfego moderado, nos quais entende-se haver carbonatação natural. As quantidades de peças distribuídas em cada grupo estão apresentadas, a seguir, no Quadro 1. 
Quadro 1 - Características dos grupos de peças de pavimento intertravado de concreto

\begin{tabular}{|c|c|c|c|c|}
\hline Grupos & Quantidade & Identificação & $\begin{array}{c}\text { Idade de } \\
\text { Ruptura }\end{array}$ & Procedimento \\
\hline 1 & 10 peças & A1 ao A10 & $>90$ dias & $\begin{array}{c}\text { Carbonatação } \\
\text { natural }\end{array}$ \\
\hline 2 & 10 peças & C1 ao C10 & $>90$ dias & $\begin{array}{c}\text { Carbonatação } \\
\text { induzida }\end{array}$ \\
\hline 3 & 10 peças & E1 ao E10 & $>90$ dias & $\begin{array}{c}\text { Sem carbonatação } \\
\text { (protegidas) }\end{array}$ \\
\hline
\end{tabular}

Para confirmação das medidas nominais, cada peça foi medida conforme a NBR 9781 (ABNT, 2013) na qual determina que a fabricante dos blocos de concreto informe suas medidas nominais de largura, comprimento e espessura. Segundo a norma, as peças devem atender as dimensões e tolerâncias máximas que são de 250 $\mathrm{mm}$ para o comprimento máximo nominal e $60 \mathrm{~mm}$ para a sua espessura máxima nominal, com uma largura mínima de $97 \mathrm{~mm}$ na área destinada a aplicação da carga no ensaio de resistência à compressão. Para a medição do comprimento, largura e espessura, foi utilizado um paquímetro com resolução de 0,1 mm.

Para verificação da resistência, foi realizado o rompimento das peças dos três grupos. Este ocorreu na mesma data, apesar de que as peças não possuíam datas da fabricação iguais, no entanto, foram rompidas com a idade superior a 90 dias.

O ensaio de resistência a compressão foi realizado conforme a NBR 9781 (ABNT, 2013), na qual estabelece condições para a realização do ensaio de resistência característica â compressão (fpk), dentre as quais estão a necessidade de as superfícies de carregamento das peças estarem retificadas e a disposição das peças sobre placas auxiliares. É válido ressaltar que a norma NBR 9781 (ABNT, 2013) estabelece que as peças sejam saturadas em água, por no mínimo vinte e quatro horas antes do ensaio, no entanto, optou-se por não realizar essa etapa afim de obter uma resistência à compressão o mais próximo da situação real.

Segundo a norma NBR 9781 (ABNT, 2013), os resultados de resistência à compressão das peças são obtidos dividindo-se as cargas de ruptura, expressa em newtons $(\mathrm{N})$, pela área de carregamento, expressa em milímetros quadrados $\left(\mathrm{mm}^{2}\right)$, multiplicando-se o resultado pelo fator $\mathrm{p}$, função da altura da peça, conforme o Quadro 2, a seguir. A partir dessa resistência, foi realizado um comparativo com a resistência especificada na norma.

Quadro 2 - Fator multiplicativo p

\begin{tabular}{|c|c|}
\hline $\begin{array}{c}\text { Espessura nominal das } \\
\text { peças }(\mathbf{m m})\end{array}$ & $\mathbf{p}$ \\
\hline 60 & 0,95 \\
\hline 80 & 1,00 \\
\hline 100 & 1,05 \\
\hline
\end{tabular}

Fonte: Adaptado de ABNT NBR 9781 (2013).

Além disso, também foi analisado a espessura de carbonatação das peças. Para isso as peças que foram expostas a esse processo, após o seu rompimento, fram submetidas ao ensaio de fenolftaleína, na qual a parte carbonatada, ou seja, a incolor, foi medida por meio de um paquímetro. Por fim, também foi analisado uma possível relação entre a profunidade de carbonatação e a resistência a compressão.

\section{Análise e discussão dos resultados}

A seguir, serão apresentados os resultados de ensaios realizados, com respectivas discussões e análise para cada propriedade. 
4.1. Resultados de resistência à compressão

Após as amostras ficarem expostas cada uma a uma situação específica, conforme apresentado na metodologia, foram realizados os ensaios previstos de resistência a compressão e profundidade de carbonatação. Nos Quadros 3, 4 e 5, a seguir, são apresentados os resultados de resistência à compressão e resistência à compressão estimada para as peças de pavimento intertravado de concreto com 16 faces que sofreram procedimento de carbonatação natural, carbonatação induzida e sem carbonatação respectivamente.

Quadro 3 - Resistência a compressão das peças de pavimento intertravado de concreto com 16 faces com carbonatação natural

\begin{tabular}{|c|c|c|c|c|c|}
\hline \multicolumn{6}{|c|}{ Carbonatação Natural (16 faces) } \\
\hline Descrição & Carga (tf) & Carga (N) & Área $(\mathrm{mm} 2)$ & $\begin{array}{c}\text { Resistência à } \\
\text { compressão (Mpa) }\end{array}$ & $\begin{array}{c}\text { Resistência à compressão } \\
\text { estimada } \\
\text { (Mpa) }\end{array}$ \\
\hline A1 & 18,92 & 189200 & 5675 & 33,34 & \multirow{10}{*}{26,43} \\
\hline A2 & 18,99 & 189900 & 5675 & 33,46 & \\
\hline A3 & 13,59 & 135900 & 5675 & 23,95 & \\
\hline A4 & 16,13 & 161300 & 5675 & 28,42 & \\
\hline A5 & 17,62 & 176200 & 5675 & 31,05 & \\
\hline A6 & 15,23 & 152300 & 5675 & 26,84 & \\
\hline A7 & 19,74 & 197400 & 5675 & 34,78 & \\
\hline A8 & 19,53 & 195300 & 5675 & 34,41 & \\
\hline A9 & 13,18 & 131800 & 5675 & 23,22 & \\
\hline A10 & 19,19 & 191900 & 5675 & 33,81 & \\
\hline
\end{tabular}

Quadro 4 - Resistência a compressão das peças de pavimento intertravado de concreto com 16 faces com carbonatação induzida

\begin{tabular}{|c|c|c|c|c|c|}
\hline \multicolumn{6}{|c|}{ Carbonatação Induzida (16 faces) } \\
\hline Descrição & Carga (tf) & Carga (N) & Área $(\mathrm{mm} 2)$ & $\begin{array}{c}\text { Resistência à } \\
\text { compressão (Mpa) }\end{array}$ & $\begin{array}{c}\text { Resistência à compressão } \\
\text { estimada (Mpa) }\end{array}$ \\
\hline $\mathrm{C} 1$ & 31,47 & 314700 & 5675 & 55,45 & \multirow{10}{*}{35,51} \\
\hline $\mathrm{C} 2$ & 18,13 & 181300 & 5675 & 31,95 & \\
\hline C3 & 18,7 & 187000 & 5675 & 32,95 & \\
\hline C4 & 28,32 & 283200 & 5675 & 49,90 & \\
\hline C5 & 20,48 & 204800 & 5675 & 36,09 & \\
\hline C6 & 22,51 & 225100 & 5675 & 39,67 & \\
\hline $\mathrm{C7}$ & 24,96 & 249600 & 5675 & 43,98 & \\
\hline $\mathrm{C} 8$ & 22,04 & 220400 & 5675 & 38,84 & \\
\hline C9 & 27,75 & 277500 & 5675 & 48,90 & \\
\hline C10 & 26,05 & 260500 & 5675 & 45,90 & \\
\hline
\end{tabular}


Quadro 5 - Resistência a compressão das peças de pavimento intertravado de concreto com 16 faces sem carbonatação (protegidas)

\begin{tabular}{|c|c|c|c|c|c|}
\hline \multicolumn{2}{|c|}{} & & & & \multicolumn{2}{c|}{ Sem Carbonatação (16 faces) } \\
Rescrição & Carga (tf) & Carga (N) & Área (mm2) & $\begin{array}{c}\text { Resincia à } \\
\text { compressão (Mpa) }\end{array}$ & $\begin{array}{c}\text { Resistência à compressão } \\
\text { estimada (Mpa) }\end{array}$ \\
\hline E1 & 21,13 & 211300 & 5675 & 37,23 & \\
\hline E2 & 15,28 & 152800 & 5675 & 26,93 \\
\hline E3 & 19,07 & 190700 & 5675 & 33,60 \\
\hline E4 & 20,83 & 208300 & 5675 & 36,70 \\
\hline E5 & 26,57 & 265700 & 5675 & 46,82 \\
\hline E6 & 17,17 & 171700 & 5675 & 30,26 \\
\hline E7 & 21,16 & 211600 & 5675 & 37,29 \\
\hline E8 & 24,56 & 245600 & 5675 & 43,28 \\
\hline E9 & 27,81 & 278100 & 5675 & 49,00 \\
\hline E10 & 20,38 & 203800 & 5675 & 35,91 \\
\hline
\end{tabular}

Diante dos resultados à compressão estimada das peças com 16 faces, é possível observar no Quadro 4 e 6 , que a resistência a compressão obtida foi inferior ao esperado, que seria de $35 \mathrm{Mpa}$, visto que a norma NBR 9781 (ABNT, 2013) estabelece a resistência a compressão das peças de pavimento intertravado de concreto para tráfego de pedestres, veículos leves e veículos comerciais de linha seja igual ou maior que 35Mpa.

Em contrapartida, a resistência à compressão estimada das peças de pavimento intertravado de concreto com 16 faces que tiveram carbonatação induzida, foi superior a 35 Mpa solicitado na norma NBR 9781 (ABNT, 2013), conforme o Quadro 4. De toda forma é interessante o aumento da resistência obtido considerando que as peças de intertravado utilizadas para pavimentação ficarão expostas por muito tempo e sendo solicitadas tanto superficialmente como em toda sua altura.

\subsection{Resultados de carbonatação}

Posteriormente feito o ensaio de resistência à compressão das peças de pavimento intertravado de concreto, foi realizado o ensaio com fenolftaleína, afim de se obter a profundidade de carbonatação das peças ensaiadas.

Dessa forma, através do ensaio com fenolftaleína, verifica-se que nas peças de pavimento intertravado de concreto com 16 faces, as amostras que tiveram maior exposição ao dióxido de carbono, ou seja, as induzidas, obtiveram uma maior profundidade de carbonatação, como esperado. Os Quadros 6, 7 e 8, a seguir, mostram os valores de profundidade de carbonatação de cada amostra e os valores médios dessa profundidade para as peças que sofreram procedimento de carbonatação natural, carbonatação induzida e sem carbonatação respectivamente. 
Quadro 6 - Profundidade de carbonatação das peças de pavimento intertravado de concreto com 16 faces com carbonatação natural

\begin{tabular}{|c|c|c|}
\hline \multicolumn{2}{|c|}{ Carbonatação Natural (16 faces) } \\
\hline Descrição & $\begin{array}{c}\text { Profundidade de } \\
\text { carbonatação (cm) }\end{array}$ & $\begin{array}{c}\text { Média da } \\
\text { profundidade (cm) }\end{array}$ \\
\hline A1 & 0,08 & \\
\hline A2 & 0,05 & \\
\hline A3 & 0,05 & \multirow{2}{*}{0,053} \\
\hline A4 & 0,05 & \\
\hline A5 & 0,05 \\
\hline A6 & 0,06 \\
\hline A7 & 0,05 \\
\hline A8 & 0,04 \\
\hline A9 & 0,08 \\
\hline A10 & 0,02 \\
\hline
\end{tabular}

Quadro 7 - Profundidade de carbonatação das peças de pavimento intertravado de concreto com 16 faces com carbonatação induzida

\begin{tabular}{|c|c|c|}
\hline \multicolumn{2}{|c|}{ Carbonatação Induzida (16 faces) } \\
\hline Descrição & $\begin{array}{c}\text { Profundidade de } \\
\text { carbonatação (cm) }\end{array}$ & $\begin{array}{c}\text { Média da } \\
\text { profundidade (cm) }\end{array}$ \\
\hline C1 & 0,25 & \\
\hline C2 & 0,08 \\
\hline C3 & 0,28 \\
\hline C4 & 0,11 \\
\hline C5 & 0,14 \\
\hline C6 & 0,09 \\
\hline C7 & 0,09 \\
\hline C8 & 0,27 \\
\hline C9 & 0,08 \\
\hline C10 & 0,30 \\
\hline
\end{tabular}


Quadro 8 - Profundidade de carbonatação das peças de pavimento intertravado de concreto com 16 faces sem carbonatação (protegidas)

\begin{tabular}{|c|c|c|}
\hline \multicolumn{2}{|c|}{ Sem Carbonatação (16 faces) } \\
\hline Descrição & $\begin{array}{c}\text { Profundidade de } \\
\text { carbonatação (cm) }\end{array}$ & $\begin{array}{c}\text { Média da } \\
\text { profundidade (cm) }\end{array}$ \\
\hline E1 & 0,05 & \\
\hline E2 & 0,06 & \\
\hline E3 & 0,06 & \multirow{2}{*}{0,05} \\
\hline E4 & 0,10 & \\
\hline E5 & 0,05 & \\
\hline E6 & 0,07 & \\
\hline E7 & 0,03 \\
\hline E8 & 0,00 \\
\hline E9 & 0,03 \\
\hline E10 & 0,05 \\
\hline
\end{tabular}

Ainda é possível observar nas Tabelas 6 e 8, que o valor médio de profundidade de carbonatação das peças que sofreram carbonatação natural e que não foram carbonatadas, foram praticamente iguais, o que se deve ao fato de o local no qual as peças foram expostas naturalmente não ficar próximo de uma via com tráfego intenso, demonstrando que ambas as condições de exposição, natural e sem carbonatação, eram similares.

\section{Conclusão}

A partir dos resultados obtidos nos ensaios realizados nas peças de pavimento intertravado do tipo 16 faces, foi possível observar uma grande variação nos resultados de resistência a compressão. Ao avaliar a resistência a compressão de peças de intertravados do tipo 16 faces e retangular, observou-se que todas as peças analisadas apresentaram resultado de resistência a compressão estimada abaixo do especificado pela norma NBR 9781 (2013). Com exceção da peça do tipo 16 faces que teve a carbonatação induzida, o restante das peças apresentou resultado de resistência a compressão estimada abaixo da resistência especificada em norma. Apesar de resistência a compressão não ser o foco da pesquisa, é importante comentar sobre esse resultado. $O$ mesmo pode estar relacionado ao fato de que a prensa utilizada estava a mais de um ano sem calibração.

Cabe ainda salientar sobre a importância de se trabalhar com fatores de segurança em dosagens de concreto para intertravados visto a possibilidade de resistência não atingir o especificado pela norma e também da mesma diminuir com tempo como aconteceu com as peças de intertravado do tipo retangular.

Também observou-se que as peças de intertravado que sofreram carbonatação induzida obtiveram maior profundidade de carbonatação como já era esperado. Confirmando assim a capacidade dessas peças de capturarem o $\mathrm{CO} 2$ auxiliando assim na diminuição da concentração desse gás na atmosfera e minimizando o impacto da industria cimnetícia no meio ambiente.

Por fim, ao verificar o aumento do resultado de resistência a compressão estimado nas peças de 16 faces que sofrem carbonatação induzida, observa-se que tal processo não impactou no comportamento mecânico dessas peças e assim não prejudicaria o desempenho do sistema de pavimentação para tráfego de veículos.

Análise da capacidade de captura de dióxido de carbono em peças de pavimento intertravado de concreto. 
Dessa forma, partir da capacidade das peças de intertravados de capturar o dióxido de carbono presente na atmosfera de forma natural e no fato de que tais peças não têm o seu comportamento mecânico impactado negativamente, indica-se um maior incentivo do uso desse tipo de pavimentação em centros urbanos onde há uma maior emissão do dióxido de carbono devido ao grande fluxo de veículos.

\section{Referências}

ABNT. NBR 9781: Peças de concreto para pavimentação - Especificação e méto dos de ensaio, 2013. ASSI, L.; DEAVER, E; ELBATANOUNY, M.; ZIEHL, P. Investigation of early compressive strength of fly ash-based geopolymer concrete. Construction and Building Materials, v. 112, p.807-815, 2016.

BEIROZ, H. Efeito Estufa. Rio de Janeiro: Simonsen - faculdades e colégios, 2011. 5 p Apostila. LIRA, Julia; ASSIS, André. Inventário de ciclo de vida do cimento brasileiro: meta-análise de dados nacionais. In: ENCONTRO NACIONAL DE TECNOLOGIA DO AMBIENTE CONSTRUÍDO, 18., 2020, Porto Alegre. Anais... Porto Alegre: ANTAC, 2020.

POSSAN, E. Captura de $\mathrm{CO} 2$ em materiais cimentícios. Estratégias para mitigação do $\mathrm{CO} 2$ na cadeia produtiva do concreto, revista IBRACON de Concreto e Construções, Fortaleza, ed. 95, p. 60-66, jul./set. 2019.

RIGO, Eduardo; OLIVEIRA, Carlos Eduardo de; POSSAN, Edna. Aplicação de modelagem matemática para fins de previsão de vida útil de estruturas de concreto sujeitas à ação de CO2. Anais do, v. 3, p. 245-256. 